\title{
The exposure and toxic effects of mercury in gold mining activities
}

\author{
Lina Eltaib ${ }^{1}$, Salah Eldeen Taj Elser Ali $^{2}$, Hind Rikabi ${ }^{1}$,*
}

${ }^{l}$ Northern Border University, Saudi Arabia

${ }^{2}$ Omdurman Islamic University, Faculty of Pharmacy, Department of

Pharmacology, Sudan

\section{Correspondence}

Hind Rikabi, Northern Border University, Saudi Arabia

Email: linasalaheldin@gmail.com

\section{History}

- Received: Nov 112018

- Accepted: Jan 162019

- Published: Feb 252019

\section{DOI :}

https://doi.org/10.15419/ajhs.v5i1.443

\section{Check for updates}

\section{Copyright}

( ) Biomedpress. This is an openaccess article distributed under the terms of the Creative Commons Attribution 4.0 International license.

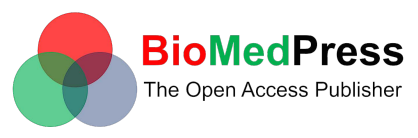

\begin{abstract}
Background: Mercury is used by artisanal — small-scale (ASM) gold miners throughout the World In 2014, the Sudanese government produced over 60 tons of gold, which make Sudan ranked Africa's third-largest gold miner. Also, Sudan is ranked the $15^{\text {th }}$ global producer. In 2015, over 1 million miners participated in gold mining and extraction. Objective: This study aimed to determine mercury health risk in Sudanese traditional gold mining activities area. Method: This is an analytical cross-sectional observational stud. The studied population was from ALTWAHEN near ABUHAMED. Urine analysis was supported by epidemiological questionnaires designed by (EPI INFO software) following WHO guidelines. Eighty-six respondents completed the questionnaire. The mercury level was determined in 58 urine sample by Petroleum Laboratories Using Direct Mercury Analyzer DMA80 instrument. The epidemiological data were analyzed by (EPI INFO). Result: $98 \%$ exceed concentration of $100 \mu \mathrm{g} / \mathrm{L}$ which contaminated concentration for occasionally exposed, mean urinary mercury concentration $2785 \mu \mathrm{g} / \mathrm{L}$, the highest mercury concentration worldwide reported by our study $10250 \mu \mathrm{g} / \mathrm{L}$, symptoms in 58 patient showed as problem finding correct word $46.6 \%$, memory problem $27.6 \%$, problem with thinking clearly $29.3 \%$, nervousness $31 \%$, sadness $46.5 \%$, sexual problem $36.2 \%$, headache $51.7 \%$, excessive salivation $43 \%$, drowsy $48.3 \%$. Conclusion: In this study, the highest urinary mercury concentration was reported $(10250 \mu \mathrm{g} / \mathrm{L})$ compared to other studies. Mercury concentration with no significant difference between the miner groups and others. Also, this study found high incidents of neurological symptoms associated with neurotoxicity. The problem with thinking significantly correlated to the age weighted by mercury concentration. Only tremor significantly related to the time living in the mining area. Otherwise, no significant relationship between mercury concentration, symptoms and time living in the area. Recommendation: conducting interventional study by using chelation therapy, gold miners should use safety tools, activation of laws and conventions (MINAMATA convention).

Key words: Activities, Exposure, Gold, Mercury, Mining, Toxic
\end{abstract}

\section{INTRODUCTION}

The first mining boom episode in Sudan gold, iron ore and copper mining activities in Nubia since 30001500 BC. In 2015, over 1 million miners participated in gold mining and extraction, with 4 million family dependents benefited from mined gold revenues. The traditional gold mining activities cover 14 of the 18 Sudanese states. In 2014, the government produced over 60 tons of gold, which maked Sudan ranked Africa's third-largest gold miner, and pushed it into the top 15 global producers ${ }^{1-3}$.

Mercury is used by artisanal and small-scale (ASM) gold miners throughout the World ${ }^{4,5}$. The heavy metals cadmium, lead, and mercury are common air pollutants emitted mainly as a result of various industrial activities.

It exists in the environment in three forms: elemental mercury (poisonous as vapor), organic mercury (methyl mercury and ethyl mercury), and inorganic mercury (mercuric mercury). All these forms have toxic health effects ${ }^{6}$.
Mercury vapor can elicit the nephrotic syndrome, characterized by excessive loss of protein (mainly albumin) in the urine, and edema ${ }^{7,8}$.

\section{Rationale and Objectives}

\section{Rationale}

Traditional gold mining using mercury to form gold amalgam is widely used in South America, Africa, and Asia. Many studies have investigated the health risk due to mercury exposure worldwide and determined health effect due to mercury exposure. In Sudan, the gold mining activities are spread. However, there is only a few studies covering this area. So, we conduct this research.

\section{Objective}

\section{General objective}

To investigate mercury health risk in Sudanese traditional gold mining activities. 


\section{Specific objective}

- To detect mercury exposure among miners and other non-miners

- To observe the general toxicity among the gold mining worker

- To observe the health effect of mercury in gold mining worker

- To observe the neurotoxicity in gold mining worker

- To measure the concentration of mercury in urine among gold mining worker

\section{METHODS}

\section{Study Design}

An analytical cross-sectional observational study.

\section{Study Area}

The study was carried in Altwahen gold mining area, located $12 \mathrm{~km}$ from Abuhamad city, in Nile river stateSudan.

\section{Study Population}

All participants are from Altwahen gold mining area included gold miners who worked in Altwahen and non-miners.

\section{Inclusion Criteria}

The study included all participant who completed the questionnaire and gave urine samples $(\mathrm{N}=58)$.

\section{Exclusion Criteria}

The study excluded participants who had neurological diseases, current malaria, current injuries from accidents, and participant who did not provide urine samples $(\mathrm{N}=27)$.

\section{Sample size}

The sample size calculated as $10 \%$ (85) of the population approximately (850).

\section{Material and methods}

The urine samples were collected in four $50-\mathrm{mL}$ plastic containers. The analysis was done in laboratories by using Direct Mercury Analyzer DMA-80 instrument.

\section{Data collection}

The questionnaire was designed as WHO guideline using EPI INFO software. Interview questionnaire was conducted with all the participants. Data were collected, analyzed, and tabulated.

\section{Data analysis}

Data analysis and presentation by the EPI INFO software and Excel program.

\section{Ethical considerations}

Ethical documents were obtained from Omdurman Islamic university ethical committee.

\section{RESULTS}

In this study a total number of 58 participants were evaluated during the data collection period. After being properly revised, data were classified and presented in tables as:

\section{Distribution According To Personal Data (N $=58$ )}

Sixty two percent of the study participants were miners. However, $55 \%$ of participants were single considering that almost $7 \%$ of our study populations were children's under 18 years old working in the field, $58.6 \%$ between (19-27 years old) Table 1 .

\section{To detect the mercury exposure among} miners and other non-miners

$65.5 \%$ of study participants has history of working as miner with mercury contact. On the other hand, 50\% reported work as the place of stored mercury containers and 46.6\% never store mercury Table 2.

\section{To observe the health effect of mercury in gold mining worker}

When we questioned participant about the health effect as a result of mercury exposure, feeling Weakness reported only by $29 \%$ and, Feel Sleepy or Drowsy reported by $48.2 \%$. On the contrary, $69 \%$ never experience palpitation, $96.5 \%$ never experienced any chronic disease or diabetes Table 3.

\section{Distribution according to general health ( $N$} =58)

In miner and none miner general health problems and other symptoms, in miners metallic taste and palpitation reported by $33 \%-36 \%$ respectively, while well drillers never experienced palpitation and only $16.6 \%$ had metallic taste. However, respiratory allergy and 
Table 1: Describes miner's personal

data

\begin{tabular}{ll}
\hline Parameter & N (\%) \\
Marital Status & \\
Single & $32(55.17 \%)$ \\
Married & $26(44.83 \%)$ \\
Age & \\
$10-18$ & $4(6.90 \%)$ \\
$19-27$ & $34(58.62 \%)$ \\
$28-35$ & $12(20.69 \%)$ \\
$36-43$ & $4(6.90 \%)$ \\
$44-51$ & $2(3.45 \%)$ \\
$52-59$ & $2(3.45 \%)$ \\
Job description & \\
Miner & $36(62.07 \%)$ \\
Well Drilling Worker & $4(6.90 \%)$ \\
Others & $18(31.03 \%)$ \\
\hline
\end{tabular}

Table 2: Distribution according to mercury exposure explains history of working as miner with mercury contact and place of storing mercury container $(\mathbf{N}=\mathbf{5 8})$

\begin{tabular}{ll}
\hline Question/Response & N(\%) \\
History Of Working As Miner With Mercury Contact & \\
No & $20(34.48 \%)$ \\
Yes & $38(65.52 \%)$ \\
Place of Stored Mercury container & \\
Home & $2(3.4 \%)$ \\
work & $29(50 \%)$ \\
Never store mercury & $27(46.6)$ \\
\hline
\end{tabular}

cough in miners reported by $27.7 \%$ and $\% 52.7 \%$ respectively, among all participants $60 \%$ reported appetite problems while sexual problems and excessive salivation reported by $36 \%$ and $43 \%$ respectively Table 4 .

\section{Distribution According To Neuropsycho- logical Status}

Headache was reported by $51.7 \%$ of the study participants, among all our participants $46.5 \%$ experience problem finding correct ward and feeling sad. On the other hand, nervousness reported by $31 \%$ and $19 \%$ had sleeping problems Tables 4, 5 and 6.
Distribution according to concentration of mercury in urine among gold mining worker

Mean mercury concentration (ppb) for well drilling was 2902.73 and 3241.49 for others compared to 2563.17 for miners and among the miners the highest was 2795.85 for washers Tables 7, 8 and 9.

\section{DISCUSSION}

In our study, the miners and others in the mining area urine sample analysis showed very high mercury level (approximately $98 \%$ ) exceed the concentration of 100 $\mathrm{ppb}$ which is the contaminated concentration for occasionally exposed. 
Table 3: Distribution According To feeling Weakness, Feel Sleepy or Drowsy, Palpitation, Chronic Disease, and Diabetes $(\mathbf{N}=\mathbf{5 8})$

\begin{tabular}{ll}
\hline Question/Response & $\mathbf{N}(\%)$ \\
Feeling Weakness & $41(70.69 \%)$ \\
Same As Usual & $8(13.79 \%)$ \\
Worse Than Usual & $9(15.52 \%)$ \\
Much Worse Than Usual & \\
Feel Sleepy Or Drowsy & $30(51.72 \%)$ \\
Same As Usual & $18(31.03 \%)$ \\
More Than Usual & $10(17.24 \%)$ \\
Much Worse Than Usual & \\
Palpitation & $40(68.97 \%)$ \\
Never & $5(8.62 \%)$ \\
At Least Once A Day & $10(17.24 \%)$ \\
At Least Once A Week & $3(5.17 \%)$ \\
At Least Once A Month & \\
Chronic Disease & $56(96.55 \%)$ \\
No & $2(3.45 \%)$ \\
Yes & \\
Diabetes & $56(96.55 \%)$ \\
No & \\
\hline
\end{tabular}

Table 4: Describes the miner and none miner general healthproblems and other symptoms

\begin{tabular}{lllll}
\hline Symptoms & Miners & Well Drilling & Others & All \\
& $\mathrm{N}=36(\%)$ & $\mathrm{N}=6(\%)$ & $\mathrm{N}=16(\%)$ & $\mathrm{N}=58(\%)$ \\
Metallic Taste & $12(33.33)$ & $1(16.6)$ & $5(31.25)$ & $31 \%$ \\
Palpitation & $13(36.1)$ & $0(0.00)$ & $5(31.25)$ & $31 \%$ \\
Feel Week & $14(38.88)$ & $1(16.66)$ & $3(18.75)$ & $31 \%$ \\
Respiratory Allergy & $10(27.77)$ & $1(16.66)$ & $2(12.50)$ & $22.4 \%$ \\
Cough & $19(52.77)$ & $2(33.33)$ & $6(37.50)$ & $46.5 \%$ \\
Nausea & $8(22.22)$ & $2(33.33)$ & $2(12.50)$ & $20.7 \%$ \\
Gingivitis & $4(11.11)$ & $0(0.00)$ & $0(0.00)$ & $6.9 \%$ \\
Excessive Salivation & $20(55.55)$ & $1(16.66)$ & $4(25.00)$ & $43 \%$ \\
Appetite Problem & $22(61.11)$ & $2(33.33)$ & $11(68.75)$ & $60 \%$ \\
Sexual Problem & $12(33.33)$ & $3(50.00)$ & $6(37.50)$ & 36.2 \\
\hline
\end{tabular}


Table 5: Neurological symptoms

\begin{tabular}{lllll}
\hline Symptoms & Miners & Well Drilling & Others & All \\
& $\mathrm{N}=36(\%)$ & $\mathrm{N}=6(\%)$ & $\mathrm{N}=16(\%)$ & $\mathrm{N}=58(\%)$ \\
Feel Prickling Aching & $2(5.5)$ & $0(0.00)$ & $0(0.00)$ & $3.4 \%$ \\
Drowsy & $18(50.00)$ & $2(33.33)$ & $8(50.00)$ & $48.3 \%$ \\
Headache & $20(55.55)$ & $7(116.6)$ & $3(18.75)$ & $51.7 \%$ \\
Problem With Eye Strain & $4(11.11)$ & $0(0.00)$ & $1(6.25)$ & $8.6 \%$ \\
Tremor & $15(41.66)$ & $2(33.33)$ & $5(31.25)$ & $38 \%$ \\
\hline
\end{tabular}

Table 6: Neuropsychological symptoms

\begin{tabular}{lllll}
\hline Symptoms & Miners & Well Drilling & Others & All \\
& $\mathrm{N}=36(\%)$ & $\mathrm{N}=6(\%)$ & $\mathrm{N}=16(\%)$ & $\mathrm{N}=58(\%)$ \\
Nervousness & $10(27.7)$ & $2(33.3)$ & $6(37.5)$ & $31 \%$ \\
Feeling Sad & $19(52.77)$ & $2(33.33)$ & $7(43.75)$ & $46.5 \%$ \\
Problem With Thinking Clearly & $13(36.11)$ & $1(16.66)$ & $3(18.75)$ & $29.3 \%$ \\
Problem Finding Correct Ward & $20(55.55)$ & $2(33.33)$ & $5(31.25)$ & $46.6 \%$ \\
Memory Problem & $10(27.77)$ & $1(16.66)$ & $5(31.25)$ & $27.6 \%$ \\
Sleep Problem & $6(16.66)$ & $2(33.33)$ & $3(18.75)$ & $19 \%$ \\
\hline
\end{tabular}

Table 7: Mercury Concentration In Urine (PPb)

\begin{tabular}{|c|c|c|c|c|}
\hline $\begin{array}{l}\text { Concentration } \\
\text { from } 3.1 \text { to } 501 \mathrm{ppb}\end{array}$ & $\begin{array}{l}\text { Concentration from } \\
610 \text { to } 1295 \mathrm{ppb}\end{array}$ & $\begin{array}{l}\text { Concentration from } \\
1452 \text { to } 2685 \mathrm{ppb}\end{array}$ & $\begin{array}{l}\text { Concentration from } \\
3173 \text { to } 5708 \mathrm{ppb}\end{array}$ & $\begin{array}{l}\text { Concentration from } \\
5744 \text { to } 10250 \mathrm{ppb}\end{array}$ \\
\hline 3.18 & 610.7 & 1452 & 3173 & 5744 \\
\hline 206.2 & 660.4 & 1556 & 3252 & 5829 \\
\hline 262.7 & 757.6 & 1622 & 3529 & 5852 \\
\hline 276.2 & 777.8 & 1764 & 3639 & 6367 \\
\hline 281.1 & 808.7 & 1964 & 3770 & 6453 \\
\hline 307.9 & 896.7 & 2028 & 3858 & 6862 \\
\hline 350.3 & 1055 & 2165 & 3932 & 6995 \\
\hline 481.8 & 1055 & 2329 & 4123 & 7598 \\
\hline 494.8 & 1098 & 2380 & 5010 & 10030 \\
\hline \multirow[t]{5}{*}{501.5} & 1135 & 2428 & 5372 & 10250 \\
\hline & 1142 & 2498 & 5708 & \\
\hline & 1148 & 2498 & & \\
\hline & 1234 & 2685 & & \\
\hline & 1295 & & & \\
\hline
\end{tabular}




\begin{tabular}{lll} 
Table 8: Mercury concentration according to job description \\
\hline Job Description & Frequency & Mean Mercury Concentration (ppb) \\
Miner & 36 & 2563.17 \\
Well Drilling Worker & 6 & 2902.73 \\
Others & 16 & 3241.49 \\
Total & 58 & 2785.4238 \\
\hline
\end{tabular}

Table 9: Miner groups mercury concentration

\begin{tabular}{lll}
\hline Miner group & $\begin{array}{l}\text { Mean mercury concentration } \\
(\mathbf{p p b})\end{array}$ & Minimum (ppb) - Maximum (ppb) \\
Gold Refiner & 2180.80 & $206.2-3252$ \\
Gold Shop Worker & 1994.65 & $350.3-1994.65$ \\
Miller & 2076.88 & $276.2-3932$ \\
Washer & 2795.85 & $3.1-3471.5$ \\
\hline
\end{tabular}

\section{P-value: 0.61174 Non-significant}

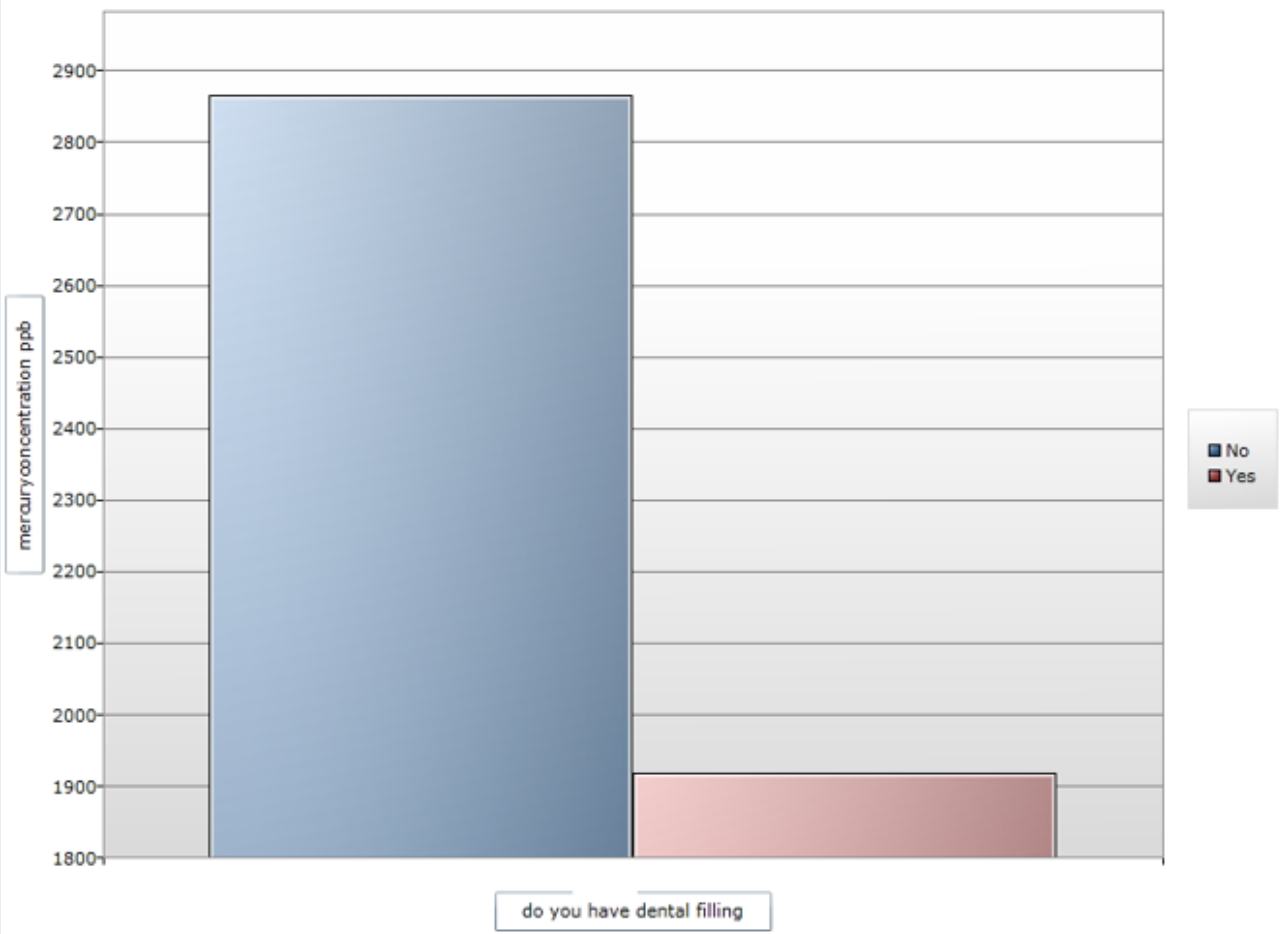

Figure 1: Means mercury concentration cross tabulated by dental filing. 


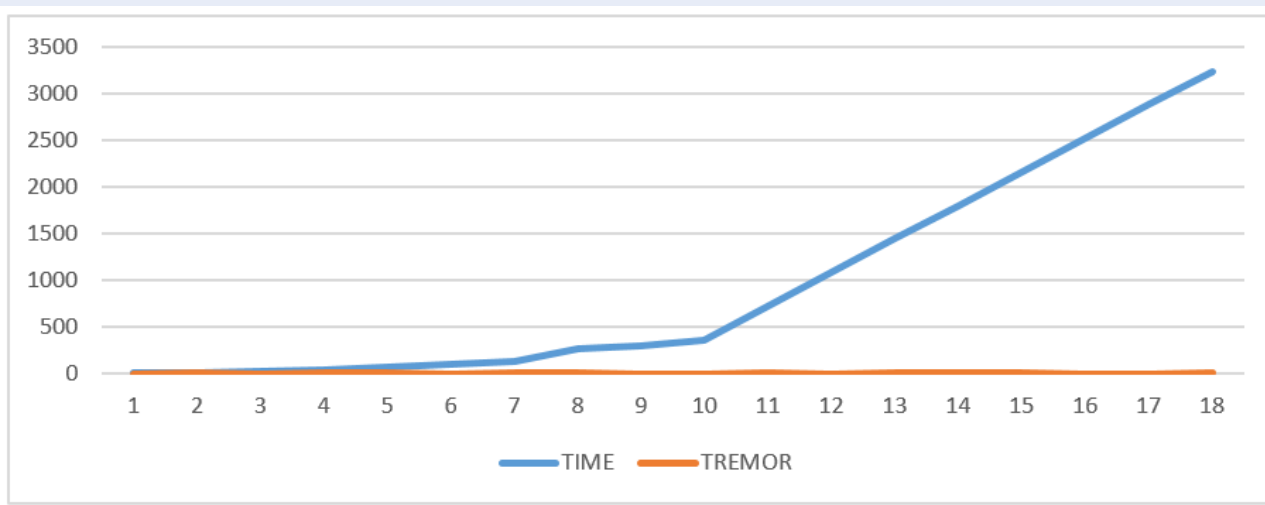

P Value: 136 Non-Significant

Figure 2: Tremor symptoms cross tabulated by time living in mining area (days).

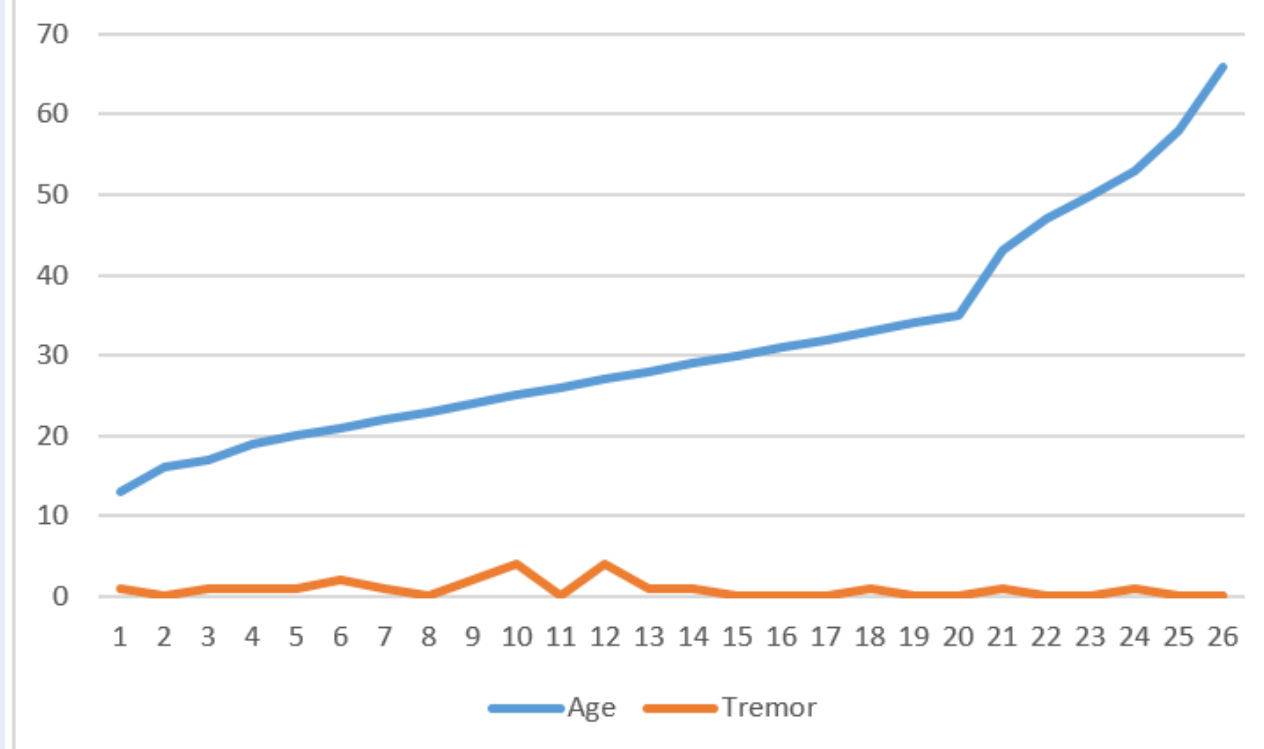

$P$ value: 0.9 Non-significant

Figure 3: Tremor Cross Tabulated By Age.

Table 10: Problem with thinking tabulated by mean age weighted by mercury concentration

\begin{tabular}{|c|c|c|c|c|}
\hline Obs & Total & Mean & Variance & Std Dev \\
\hline 37540.1000 & 897014.0000 & 23.8948 & 141609.5922 & 376.3105 \\
\hline 102409.4780 & 3257274.3500 & 31.8064 & 372216.9115 & 610.0958 \\
\hline 21605.0000 & 461141.0000 & 21.3442 & 52414.1701 & 228.9414 \\
\hline
\end{tabular}




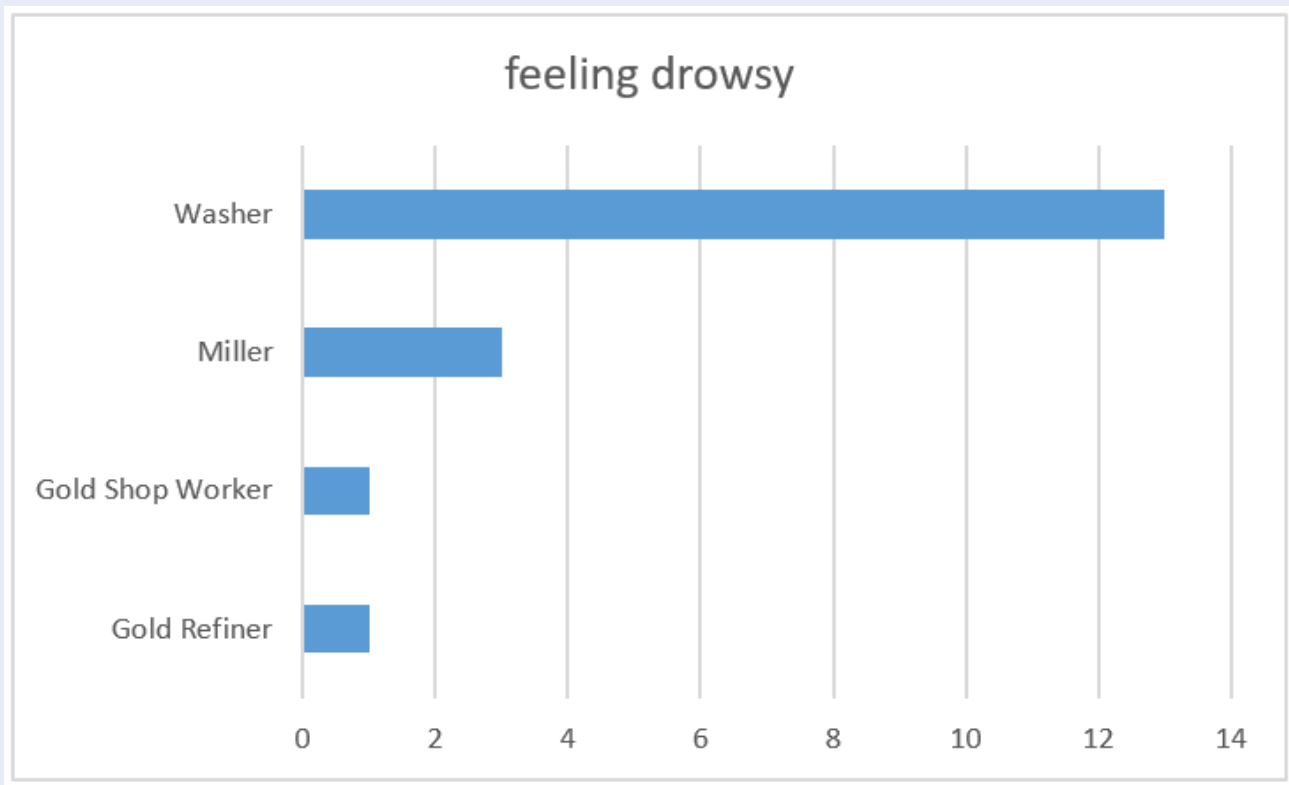

\section{$\mathrm{P}$ value :0.7 Insignificant}

Figure 4: Feeling Drowsy Cross Tabulated By Miner Groups.

Rosa et al. detected the mercury level in urine in $22 \%$ of the workers in gold shops in Brazil $\left(\mathrm{Hg}<50 \mathrm{ppm}^{9}\right)$ while in this research $100 \%$ the gold shop worker contaminated by mercury with the mean mercury concentration of $1994.6500 \mathrm{ppb}$. These gold shop worker stored mercury in their shops, and they continuously smell mercury vapor in their shops.

However, in this research in the mining area, there were non-miner workers such as coffee boys, merchants, and tailors, etc. They represent $31 \%$ of our research participants with the mean urinary mercury level for non-miners was $3241.49 \mathrm{ppb}$ which is an extremely high value compared to occasional exposure or non-exposure according to the guidelines. Oosthuizen et al. studied in South Africa and found 14 (50\%) of the urine samples exceeded the guideline for mercury in urine $(<5.0 \mu \mathrm{g} / \mathrm{g}$ creatinine) for those not exposed occasionally ${ }^{10}$. The authors concluded that some individuals might be occasionally exposed to mercury through small-scale gold mining activities. The non-miners in our study were exposed to mercury due to their work in the contaminated area in the mining work place.

The gold refiner in our study have the mean urinary mercury level of $2180.80 \mu \mathrm{g} / \mathrm{l}$ as Hurtado J. ${ }^{11}$ defined them in a term of "smelter". The high level of mercury is because they small the vapor of mercury in their regular job.
Hurtado et al. in a study in Peru ${ }^{11}$, found high levels (mean $728 \mu \mathrm{g} / \mathrm{L}$ ) of mercury in the urine of those directly involved in smelting $(\mathrm{N}=6)$, compared to the controls $(4 \mu \mathrm{g} / \mathrm{L})$. The mean level of mercury in urine for all participant in our study was $2785.4238 \mathrm{ppb}, \mathrm{N}$ $=(58)$ which is a unique finding because it was the highest urinary mercury level reported. On the other hand, in Tanzania ${ }^{12}$, urinary mercury concentrations found in $36 \%$ of individuals $(\mathrm{N}=45)$ involved in amalgamation were between 50 and $100 \mu \mathrm{g} / \mathrm{g}$ creatinine, with four samples $>100 \mu \mathrm{g} / \mathrm{g}$ creatinine. The mean mercury level in control urine samples was $5 \mu \mathrm{g} / \mathrm{g}$ creatinine.

This study is one of a few studies in Sudan aimed to evaluate the mercury toxicity among Sudanese people. Tayrab et al. ${ }^{13}$, conducted a study in Abu Hamad and found a significant increase in serum mercury levels in the gold miners $\mathrm{N}$, serum mercury level (1.40 $\pm 0.94 \mu \mathrm{g} / \mathrm{L})$ ). In our study, we agree that there is a significant increase in biological parameter urinate mercury level. We also found that $20 \%$ of our participants had a respiratory allergy, $72 \%$ of these cases were due to dust and smelling of mercury vapor. One of our findings was that $15 \%$ of those have productive cough (N 26) mentioned they have bloody color sputum. This is very important because the color of ores is red. So, that is the color of inhaled dust, not blood $^{14}$. 
Tayrab et al. concluded that forced expiratory volume in the first second (FEV1) and forced vital capacity (FVC) decreased but with no statistical significance ${ }^{13}$. The washers in our study were those were involved in washing the ores with mercury. They contacted with mercury topically with their hands. We found themean urinary mercury level of the washer was 2795.85 ppm (N 24). The mercury level of the washer was significantly higher compared to the values reported by Hursh et al. ${ }^{15}$. Hursh et al. concluded that dermal absorption of elemental mercury is limited by estimating that dermal absorption only contributed approximately $2.6 \%$ of the absorbed mercury following exposure to elemental mercury vapor in the air; the other 97.4\% occurred through inhalation ${ }^{15}$.

The result of this study showed no significant relationship between amalgam filing and mercury concentration, which is the same as Hursh et al. ${ }^{15}$ that there is no relationship between mercury concentrations in lower parts of the brain and the number of amalgam fillings in the mouth.

This result showed significantly high mercury level in urine although Afnan Abuyazed in her research ${ }^{16}$ Mercury Pollution from Artisanal Gold Mining Activities in Abo Hamad Sudan showed that mercury concentration in Sudanese hair of gold mining worker was significant. In this research, the unique urinary mercury level with the mean 2785.4238 ppb was due to the use of urinary mercury as the biological monitor. Clarkson et al. found that urine and feces are the main excretory pathways of elemental mercury and inorganic mercury compounds in humans, with an absorbed dose half-life of approximately 12 months) ${ }^{17}$. After a short-term high-level mercury exposure in humans, urinary excretion accounts for $13 \%$ of the total body burden. After long-term exposure, urinary excretion increases to $58 \%$.

In this study, mercury poisoning symptoms was found in $46.6 \%$ of the participants including memory problem $(27.6 \%)$, problem with thinking clearly (29.3\%), nervousness (31\%), sadness $(46.5 \%)$, sexual problem $(36.2 \%)$, headache $(51.7 \%)$, excessive salivation (43\%), drowsy (48.3\%). These results showed no correlation between symptoms and urinary concentration, however one of our research limitations was the feasibility to investigate the renal toxicity. However, neurological symptoms and neuropsychological and other symptoms are present in high percentage tremor but with no significant correlation with the concentration of mercury in urine.

Aks et al. found that there was no correlation between symptoms and urinary and blood concentration of mercury ${ }^{18}$, which supports our findings. This observation may be related to other co-founding factors.

One of our unique findings was that the tremor was significantly associated with the staying time in the mining area $(p=0.0136)$. Although there is no significant correlation between the symptoms and the concentration of mercury in urine, the time of living in the mining area is one of important co-founders suggested by our study.

In this research, there was no significant relation between the concentration of mercury and the time of living in the mining area, which may be justified because of the toxicodynamic properties of mercury that there is a difference in elimination rate of mercury over time. In the literatures, Clarkson et al. found that the urine and feces are the main excretory pathways of elemental mercury and inorganic mercury compounds in humans, with an absorbed dose half-life of approximately 1-2 months ${ }^{17}$. After a short-term high-level mercury exposure in humans, urinary excretion accounted for $13 \%$ of the total body burden. After long-term exposure, urinary excretion increases to $58 \%$.

In the epidemiological questionnaire, approximately $40 \%(\mathrm{~N}=36)$ of the responders reported that they experienced hand tremor. Fawer et al. ${ }^{19}$ also concluded that tremor was greater in the exposed group than in controls $(P<0.001)$ and was significantly related to the duration of exposure and age. We found a significant relationship between tremor a and duration of exposure but the age had no significant contribution to our research.

The neurotoxicity of mercury from occasional exposure is well-known. Ehrenberg et al. ${ }^{20}$, mentioned that there is a significant effect on tremor or cognitive skills or other central nervous system effects among groups exposed occasionally to similar or slightly higher levels of mercury. Tremor, abnormal Romberg test, dysdiadochokinesis, and difficulty with heel-totoe gait were also observed in thermometer plant workers.

In the epidemiological questionnaire, the result showed $5.5 \%$ of miners felt prickling aching, others non-miner had no such symptoms. This is may be due to miners being in direct contact with mercury. $50 \%$ of miners felt drowsy, and $50 \%$ of others non-miner felt drowsy, which might be a sign of air pollution in the area. Our result showed $51 \%$ of participants had headache, and $29 \%$ reported the problem in thinking clearly, $64.5 \%$ reported the problem in finding correct ward while $20 \%$ of this group reported it was much worse than usual. All these signs suggested that $\mathrm{Su}-$ danese gold mining had neurotoxicity signs due to 
contamination of the mining area. 27\% (N 58) had memory problem. Our results showed in table 3.5.2 the age and problem with thinking clearly had a very a significant result weighted to mercury concentration $\mathrm{p}$-value (0.006). Children at school age in the minidng area are at risk of decreased cognitive function.

Meyer-Baron et al. ${ }^{21}$ conducted a review of 18 epidemiological studies dealing with occupational exposure to inorganic mercury in workers with mean levels of internal exposures in the range 3-192 $\mu \mathrm{g} / \mathrm{g}$ creatinine showed associations with attention, memory, motor performance and exposure, although the quantitative dose-response relationships could not be established.

Regarding neurobehavioral effects, this study reported that $48 \%$ of the participants $(\mathrm{N}=58)$ feeling sad, $31 \%(\mathrm{~N}=58)$ feeling nervous neurobehavioral effects, increasing hostility and anxiety levels, and decreasing mental stability and inferiority complex. The neurobehavioral effect of mercury in mining area may be realted to the violence rate in the mining area. A limitation of our research is there was no accessibility to evaluate renal toxicity. However, recently, a WHO review concluded, on the basis of existing studies, that adverse effects on the kidney usually occur at exposures higher than those that induce neuro-physiological effects. There is a scientific gap in human's lowest harmful or non-adverse exposure levels, especially for long-term exposure. The result of this study showed high neuro-physiological symptoms. However, the effect of mercury on the renal system was not evaluated.

This result documented the highest level worldwide mercury concentration which indicates chronic toxicity. Although the study evaluated the health effect of gold mining worker, we could predict the environmental pollution by employing the regression line determined by ${ }^{22,23}$, a urinary level of $2785.4 \mathrm{ppb}$ could be calculated to estimate the airborne mercury concentration. By using personal breathing zone mercury measurements, it was estimated that in continuous $8 \mathrm{~h}$ /day occupational exposure, an airborne mercury concentration of $1 \mathrm{mg} / \mathrm{m} 3$ leads to an average urinary mercury concentration of $1.4 \mathrm{mg}(7 \mu \mathrm{mol}) /$ liter (variation between individual studies, $0.7-2.3 \mathrm{mg}$ [3.5$11.5 \mu \mathrm{mol}] /$ liter (82).

Studies conducted by Lindstedt et al. ${ }^{23}$, reported a correlation between airborne mercury and mercury in blood and urine. However, results are not consistent across studies. Also, it is unknown whether the ratio between concentrations in urine and blood is constant at different exposure levels.
This study showed that the Hugh level of mercury in urine sample taken from Altwahen area $12 \mathrm{~km}$ away from Abou Hamad in Nile river state (Sudan) (mean $2785.4238 \mathrm{ppm}$ ) and tremor $37 \%$, which is different from the research done by global mercury project ${ }^{13}$. The study showed that the population's exposure did not lead to high mercury levels in blood, hair, or urine. The only symptom of chronic mercury intoxication observed were standing tremors and eyelids, lips, tremors in $40 \%$ of participants. The study found that it was not possible to demonstrate that there was any relationship between these signs and mercury use or mercury levels in the blood, urine or hair sample. This difference between our findings and the global mercury project result may be due to differences in many factors including research methodology, geographical area location, amount of mercury use, and workplace method. Baeuml et al. ${ }^{24}$ reported mercury levels also differ considerably between countries, which reflects a diverse background burden due to different fish eating habits and different workplace methods.

\section{CONCLUSIONS}

The aim of the study was to test mercury poisoning in small gold mining activity at Abo- Hamad city in AlTawahean area. We found that the mean of mercury concentration in urine was $2785 \mathrm{ppb}$, which indicated a high toxicity level. The highest mercury concentration reported by this research was $10250 \mathrm{ppb}$ with no significant difference between miner groups and others. Also, we found high incidents of neurological symptoms associated with neurotoxicity.

Problem with thinking clearly has significant correlation to age weighted by mercury concentration. Tremor is definitely related to the time living in the mining area. Otherwise, there was no significant relationship between mercury concentration, symptoms and time living in the area.

\section{RECOMMENDATION}

Interventional study should be done using chelating therapy. Renal toxicity should be evaluated in people living in gold mining areas. Gold miners should use safety tolls (gloves, mask, etc.). Monitoring the environment and organic mercury in water. Working time in the mining area should be adjusted. Studies at Abo-hamad city should be conducted to evaluate the community exposure to mercury including pregnant women and children at school age. Toxicological study should be conducted to measure mercury in Nile river fish. Alternative technologies should be implemented to reduce mercury emission. 


\section{COMPETING INTERESTS}

Authors have no conflict of interest.

\section{AUTHORS' CONTRIBUTIONS}

Conceptualization of work \& its realization was done by Dr.Salah Altag, all authors participate in acquisition of data, analysis and interpretation of data; The correspondent author Dr.Lina and Dr.Hind participate in drafting the article or revising it critically for important intellectual content; All authors give final approval of the version to be submitted and any revised version.

\section{REFERENCES}

1. of Sudan CB. Annual Reports 2002-2014;.

2. Co Report on Artisanal Mining Impacts prepared for Ministry of Finance 2015;

3. of Minerals M. Reports 2014-2015;

4. Taylor H, Appleton JD, Lister R, Smith B, Chitamweba D, Mkumbo O. Environmental assessment of mercury contamination from the Rwamagasa artisanal gold mining centre, Geita District, Tanzania. Sci Total Environ. 2005;343(1-3):11133. Available from: 10.1016/j.scitotenv.2004.09.042.

5. Rosa RS, Müller RC, Alves CN, Sarkis JE, Bentes MH, Brabo $E$, et al. Determination of total mercury in workers' urine in gold shops of Itaituba, Pará State, Brazil. Sci Total Environ. 2000;261(1-3):169-76. Available from: 10.1016/S00489697(00)00641-0.

6. Ibrahim D, Froberg B, Wolf A, Rusyniak DE. Heavy metal poisoning: clinical presentations and pathophysiology. Clin Lab Med. 2006;26(1):67-97. Available from: 10.1016/j.cll.2006.02. 003.

7. World HO. Air quality guidelines for Europe; 2000 .

8. Rosa RS, Müller RC, Alves CN, Sarkis JE, Bentes MH, Brabo $E$, et al. Determination of total mercury in workers' urine in gold shops of Itaituba, Pará State, Brazil. Sci Total Environ. 2000;261(1-3):169-76. Available from: 10.1016/S00489697(00)00641-0.

9. Rosa RS, Müller RC, Alves CN, Sarkis JE, Bentes MH, Brabo $E$, et al. Determination of total mercury in workers' urine in gold shops of Itaituba, Pará State, Brazil. Sci Total Environ. 2000;261(1-3):169-76. Available from: 10.1016/S00489697(00)00641-0.

10. Oosthuizen MA, John J, Somerset V. Mercury exposure in a low-income community in South Africa. S Afr Med J. 2010;100(6):366-71. Available from: 10.7196/SAMJ.3863.

11. Hurtado J, Gonzales GF, Steenland K. Mercury exposures in informal gold miners and relatives in southern Peru; 2013.
12. van Straaten P. Human exposure to mercury due to small scale gold mining in northern Tanzania. Sci Total Environ. 2000;259(1-3):45-53. Available from: 10.1016/S0048-9697(00) 00548-9.

13. Tayrab E, Elrahim MAA, Elameen MEA, Yassin A, Kodi A. Human Mercury Exposure Associated with Artisanal Gold Miners in Sudan. Int J Earth Environ Sci. 2016;1(118). Available from: 10.15344/ijees/2016/118.

14. Kudsk FN. The influence of ethyl alcohol on the absorption of mercury vapour from the lungs in man. Acta Pharmacol Toxicol (Copenh). 1965;23(2):263-74. Available from: 10.1111/ j.1600-0773.1965.tb03593.x.

15. Hursh JB, Cherian MG, Clarkson TW, Vostal JJ, Mallie RV. Clearance of mercury (HG-197, HG-203) vapor inhaled by human subjects. Arch Environ Health. 1976;31(6):302-9. Available from: 10.1080/00039896.1976.10667240.

16. Mohamed AA, Koveke EP, Ohira SI, Toda K. Mercury Pollution from Artisanal Gold Mining Activities in Sudan. Basha Research Centre; 2015. p. 062-064.

17. Clarkson TW, Magos L, Cox C, Greenwood MR, Amin-Zaki L, Majeed MA. Tests of efficacy of antidotes for removal of methylmercury in human poisoning during the Iraq outbreak. J Pharmacol Exp Ther. 1981;218(1):74-83.

18. Aks SE, Erickson T, Branches FJ, Naleway C, Chou HN, Levy P, et al. Fractional mercury levels in Brazilian gold refiners and miners. J Toxicol Clin Toxicol. 1995;33(1):1-10. Available from: 10.3109/15563659509020208.

19. Fawer RF, de Ribaupierre Y, Guillemin MP, Berode M, Lob M. Measurement of hand tremor induced by industrial exposure to metallic mercury. Br J Ind Med. 1983;40(2):204-8. Available from: 10.1136/oem.40.2.204.

20. Ehrenberg RL, Vogt RL, Smith AB, Brondum J, Brightwell WS Hudson PJ. Effects of elemental mercury exposure at a thermometer plant. Am J Ind Med. 1991;19(4):495-507. Available from: 10.1002/ajim.4700190407.

21. Meyer-Baron M, Schaeper M, Seeber A. A meta-analysis for neurobehavioural results due to occupational mercury exposure. Arch Toxicol. 2002;76(3):127-36. Available from: 10 1007/s00204-002-0327-9.

22. Roels H, Abdeladim S, Ceulemans E, Lauwerys R. Relationships between the concentrations of mercury in air and in blood or urine in workers exposed to mercury vapour. Ann Occup Hyg. 1987:31(2):135-45.

23. Lindstedt G, I IG, Holmgren B, Jonsson T, Karlsson G. Individual mercury exposure of chloralkali workers and its relation to blood and urinary mercury levels. Scand J Work Environ Health. 1979;5(1):59-69. Available from: 10.5271/sjweh.2665.

24. Baeuml J, Bose-O'Reilly S, Gothe RM, Lettmeier B, Roider G, Drasch $G$. Human biomonitoring data from mercury exposed miners in six artisanal small-scale gold mining areas in Asia and Africa. Minerals (Basel). 2011;1(1):122-43. Available from: 10.3390/min 1010122 . 